\title{
Os sentidos do Golpe de 1964 nos livros didáticos de história (1970-2000): entre continuidades e descontinuidades ${ }^{1}$
}

\author{
Mateus H. F. Pereira ${ }^{2}$
}

Andreza C. I. Pereira

Nossa pesquisa pretende pensar sobre o Golpe de 1964, através da história escrita por autores de livros didáticos. Utilizamos como corpus documental livros editados de 1970 até 2000, a fim de apreender dimensões das metamorfoses do acontecimento. Pretendemos, assim, compreender e explicar como esses impressos de ampla circulação buscaram "origens" com fins de realizar didaticamente um trabalho de luto sobre o "acontecimento traumático" no tempo presente do próprio evento.

Palavras-chave: Golpe Militar de 1964 - acontecimento - livro didático de história

The senses of the Blow of 1964 in the history text books (1970-2000): between continuous and discontinuous

Our research intends to think on the Blow of 1964, through written history by authors of text books. We used as documental corpus edited books from 1970 up to 2000, in order to apprehend dimensions of the event's metamorphoses. We intend to understand and to explain as those printed papers of wide circulation searched for "origins" aiming

\footnotetext{
${ }^{1}$ Artigo recebido e aprovado para publicação em setembro de 2009.

${ }^{2}$ Mateus Henrique de Faria Pereira é professor do Departamento de História da Universide Federal de Ouro Preto (UFOP), Andreza Cristina Ivo Pereira é graduada em história pela Universidade do Estado de Minas Gerais (UEMG). Agradecemos as sugestões de Juliana Melo, Flávia Lemos, Miriam Hermeto e dos pareceristas da revista Tempo. E-mail: matteuspereira@gmail.com e mundodemaya@ymail.com. Apoio: FAPEMIG e CNPq.
} 
didactically accomplishing a mourning work on the "traumatic event" in the present time of the own event.

Keywords: The Blow of 1964 - event - history text books

\section{Les sens du Coup d'État de 1964 dans les livres didactiques d'histoire (1970- 2000): entre continuites et descontinuites}

Notre recherche veut penser sur le Coup d'État de 1964, à travers l'histoire écrite par des auteurs de livres didactiques. Nous utilisons comme source livres édités de 1970 jusquà 2000, afin d'appréhender des dimensions des métamorphoses de l'événement. Nous prétendons, ainsi, comprendre et expliquer comme ces livres de large circulation ont cherché “origines" avec des fins de réaliser didactiquement un travail de deuil sur l'“ événement traumatique" dans le temps présent de l'événement lui-même.

Mots-clés: Coup d'État de 1964 - événement - livre didactique d'histoire

Neste artigo, pretendemos problematizar algumas construções de sentido do Golpe de 1964, construídas por autores de alguns livros didáticos de história, editados no período entre 1970 e $2000 .^{3}$ Buscaremos analisar as diversas interpretações existentes principalmente no que se referem às "origens" do evento, na intenção de compreender e explicar algumas das permanências e mudanças nos sentidos atribuídos ao "acontecimento traumático"4 na temporalidade própria do corpus documental de nossa pesquisa, isto é, pretendemos compreender e explicar as metamorfoses do Golpe de 1964 por meio do diálogo que procuramos estabelecer entre as interpretações dos livros didáticos escolhidos.

É preciso destacar que de 1973 até 2000 a historiografia e o ensino de história mudaram em vários aspectos, assim como os olhares sobre o golpe também. A intenção deste texto é captar, mesmo que de forma lacunar, os sentidos produzidos pelos livros. Compreendemos que essa ênfase nos sentidos apresenta um risco: a perda de aspectos da "historicidade" dos livros. Pensamos que esse risco é válido, na medida em que os livros didáticos de história analisados são aqui entendidos

\footnotetext{
${ }^{3}$ A seleção dos livros didáticos utilizados partiu de um levantamento prévio, por meio de informações de editoras e autores, das obras mais representativas e utilizadas no estado de Minas Gerais desde os anos 1970. Levamos em consideração, também, a quantidade de aparição de determinados livros em bibliotecas públicas e escolares. Ver anexo 1 e 2.

${ }^{4}$ Sobre o conceito de "acontecimento traumático", ver Paul Ricoeur, Écrire L'Histoire du Temps Present, Paris, Seuil, 1991. Para o conceito de trauma em Freud, ver, em especial, S. Freud, Obras Completas, Buenos Aires, Amorrortu, vol. XXIII, 1986, pp.70-73.
} 
como os intérpretes doadores de sentidos ao "acontecimento traumático" Golpe de $1964 .{ }^{5}$ Dessa maneira, pretendemos, mergulhar na descontinuidade da construção e produção de sentidos do "acontecimento traumático" 6 a partir de uma escala específica: os livros didáticos de história produzidos entre 1970 e 2000.

\section{Sentidos e "origens" do "acontecimento traumático" 1964}

Nesse item, procuramos descrever e analisar as mudanças de sentido realizadas pelos autores de livros didáticos de história acerca do Golpe de 1964, enfatizando as causalidades ou as "origens" utilizadas nos livros, em suas narrativas. Apontamos algumas das mudanças mais significativas, observadas nas abordagens acerca do Golpe realizadas pelos autores de livros didáticos. A tipologia construída procura fornecer alguns elementos para que possamos problematizar as "origens" do Golpe de 1964. As "origens" do golpe cumprem o papel de escalas de observação para efetuarmos jogos de escalas. ${ }^{8}$

\footnotetext{
${ }^{5}$ De algum modo, tendo em vista essa escolha perdemos parte das dinâmicas contextuais de produção, circulação e apropriação dos livros. Neste aspecto, apoiamos-nos, também, na crítica de Jaques Revel a ideia de contexto no singular - por meio dos usos retórico, argumentativo e interpretativo - para construir efeitos de "verdade e/ou realidade" a determinada argumentação. Pretendemos, assim, por via dos textos dos livros didáticos contribuir para aquilo que o autor chama de "construir a pluralidade de contextos". Jaques Revel. "Microanálise e construção do social", In: Jogos de escalas: a experiência da microanálise, Rio de Janeiro, FGV, 1998, p. 27. A referida escolha se justifica também pelos limites de páginas que um artigo comporta. Por essas razões, também, optamos por não referirmos à data de primeira edição dos livros analisados, pois muitas vezes de uma edição para outra há grandes transformações explicativas. Referimos-nos apenas, nesse sentido, ao ano de publicação dos livros analisados.

${ }^{6}$ Trata-se aqui de seguir as orientações metodológicas sugeridas por Louis Queré, "Un évenément indecidable?", Espace Temps, 64-65, Paris, 1997, p. 4.

${ }^{7}$ Segundo Miriam Hermeto de Sá Mota, a causalidade não se refere apenas "às relações de causaefeito simples, mas à explicação de processos de transformação complexos, que compreendem as permanências e transformações que se desenvolveram entre um estado inicial e um estado final demarcados pelo observador". Miriam Hermeto de Sá Motta, "Um estudo sobre a causalidade no ensino de História", Belo Horizonte, Faculdade de Educação da Universidade Federal de Minas Gerais, 2002, Dissertação de Mestrado, p.24.

${ }^{8}$ Metodologicamente, nosso trabalho insere-se no que Paul Ricoeur denomina grande conquista ou liberdade metodológica do trabalho do historiador: o jogo de escalas, pois indica uma saída para a falsa alternativa que estruturava o trabalho histórico entre os partidários do acontecimento e os da longa duração. Desse modo, em cada escala, veem-se aspectos que não são vistos em outra e cada olhar tem a sua legitimidade. Paul Ricoeur, La mémoire, l'histoire, l'oubli. Paris: Seuil, 2000. Ver, também, Jaques Revel (org.), Jogos de escalas: a experiência da microanálise, Rio de Janeiro, FGV, 1998.
} 


\section{“Origem”: crise econômica, política e social}

A crise econômica, política e social do país é uma das principais causas para o desencadeamento do Golpe de 1964 para muitos livros didáticos. Análises factuais se mesclam com análises conjunturais. Maria Januária Vilela Santos, autora do livro História do Brasil (1979), ${ }^{9}$ destinado à $6^{a}$ série, afirma que "durante a presidência de João Goulart, o Brasil foi agitado por manifestações políticas, greves, aumento da inflação e do custo de vida", e que "a partir de 1963, a crise econômica e política agravou-se, ocorrendo inclusive atos de indisciplina dentro das Forças armadas". No dia 31 de março de 1964, teve "início, em Minas Gerais, um movimento contra o governo". A autora ainda afirma que o presidente foi "deposto em 24 horas e partiu para o Uruguai, como exilado político". ${ }^{10}$

É importante destacar que há incorreção no que se refere à saída de Jango imediatamente para o Uruguai. Esta incorreção, de algum modo, legitima o Golpe, pois a vacância anunciada, em 1 de abril de 1964, por Ranieri Mazzili, foi inconstitucional, na medida em que João Goulart permaneceu no país até o dia 4 de abril de 1964. A inserção ou não da temática da vacância nas narrativas presentes nos livros didáticos, em boa parte, indica o caminho que muitos dos autores dos livros da primeira geração posterior a 1964 "escolheram" para compreender e explicar os eventos. Podemos dizer que essa "escolha", presente em grande número dos livros mais recentes também, contribui para manter a ideia da inevitabilidade do Golpe, conforme será analisado mais adiante.

Francisco Alencar, Lúcia Carpi Ramalho e Marcus Venício Toledo Ribeiro, autores do livro História da Sociedade Brasileira (1985), ${ }^{11}$ afirmam que o Governo Goulart iniciava-se em um momento de crise econômica e financeira. "Crise

\footnotetext{
${ }^{9}$ Maria Januária Vilela Santos, História do Brasil, 6a série, São Paulo, Ática, 1979, p. 185. É preciso destacar que, em geral, os livros didáticos são produzidos por uma variedade de atores. Ver, por exemplo, Kazumi Munakata, "Histórias que os livros didáticos contam, depois que acabou a ditadura no Brasil”, In: Marcos Cezar Freitas (org.), Historiografia Brasileira em Perspectiva, São Paulo, Contexto, 2003. No entanto, utilizamos o critério "autor" para analisar as construções de sentido sobre o Golpe de 1964, dentre outras razões, porque uma parte significativa de professores, alunos e público geral conhece e utiliza os livros tomando o(s) nome(s) do(s) autor(es) como referência. O que nos importa, nesta reflexão, não é a categoria autor em si e sim a narrativa produtora de sentido.

${ }^{10}$ Maria Januária Vilela Santos, História do Brasil, 6a série, São Paulo, Ática, 1979, p. 185.

${ }^{11}$ Francisco Alencar; Lúcia Carpi Ramalho; Marcus Venício Toledo Ribeiro, História da Sociedade Brasileira, Rio de Janeiro, Editora Ao livro Técnico, 1985, pp. 288-306. A obra não explicita a que série se destina.
} 
típica de um país dependente, cuja industrialização se baseava na substituição de importações e na alta exploração da força de trabalho." Percebemos aí uma análise com certa "tendência estrutural", pois aponta a forma pela qual ocorreu a industrialização "tardia" brasileira como origem da crise que gerou o Golpe. Os autores ainda afirmam que o governo intentava uma política nacionalista reformista - em momento algum, explicita-se o que se queria dizer com isso - em uma "etapa em que a burguesia e as classes trabalhadoras tinham sofrido transformações substanciais". Teria sido a política de Goulart a causadora do

colapso final do estado populista. (...) Um outro fenômeno iria contribuir também para o colapso do pacto populista: a ascensão de movimentos reivindicatórios dos trabalhadores rurais, os quais, aos poucos, vinham adquirindo conteúdos políticos. ${ }^{12}$

No livro História (1991), ${ }^{13}$ escrito por Kátia Alves e Regina Belisário, destinado ao Ensino Fundamental, a defesa da campanha das reformas de base por parte de Jango teria "provocado as suspeitas do centro, quanto aos seus objetivos finais. A situação se complicou ainda mais, quando o Primeiro Ministro, Tancredo Neves, renunciou. Surgiram greves, manifestações de rebeldia, assaltos". Outros aspectos como "o agrupamento das lutas ideológicas nos períodos anteriores; o crescimento da inflação, do custo de vida e a violenta pressão salarial que multiplicava os movimentos grevistas" e "os choques políticos entre a esquerda e os grupos conservadores que combatiam a proposta das reformas" também seriam fatores que teriam levado ao golpe.

\section{“Origem": renúncia de Jânio Quadros}

Nos livros analisados, há a perpetuação de uma representação acerca da personalidade de Jânio Quadros. O ex-presidente sempre é retratado como um homem carismático; porém, imprevisível. Raymundo Campos, autor do livro História do Brasil, de 1983, ${ }^{14}$ por exemplo, destinado ao Ensino Médio, afirma que "na manhã de 25 de agosto de 1961, em carta ao Congresso Nacional, Jânio Quadros renunciava ao seu mandato. O gesto do presidente permanece sem explicações definitivas, mas ao que parece, tratou-se de uma tentativa de golpe”. Elian Alabi Lucci,

\footnotetext{
12 Ibidem.

${ }^{13}$ Kátia Corrêa Peixoto Alves; Regina Célia de Moura Gomide Belisário, História. Ensino Fundamental, vol. 4, Belo Horizonte, Vigília, 1991, pp. 129-131.

${ }^{14}$ Raymundo Campos, História do Brasil, Ensino Médio, São Paulo, Atual, 1983, p. 224.
} 
por sua vez, na obra História do Brasil: o império, a república e o Brasil contemporâneo, de $1985,{ }^{15}$ destinada ao Ensino Médio, afirma que, apesar do presidente Jânio Quadros ter tido uma carreira rápida e brilhante, não cuidou de obter o apoio parlamentar, indispensável para a execução de um plano de governo. Ao optar por legislar o país só por decretos, acabou provocando um conflito inevitável com o Poder Legislativo. Dessa forma, perante as pressões internas e as dificuldades crescentes de governar o país sozinho, o Presidente preferiu renunciar. Cláudio Vicentino, autor do livro História: memória viva, de 1994, ${ }^{16}$ afirma que "a renúncia foi uma manobra política fracassada de Jânio Quadros, uma trama para reforçar seu próprio poder. O golpe fundava-se no temor de setores da sociedade e de parte da opinião pública diante de um governo dirigido por Jânio Quadros”.

Tendo em vista essa permanência, a renúncia de Jânio Quadros, em 1961, foi apontada como uma das causas centrais do golpe militar em boa parte dos livros dos anos 1970 e 1980, porém ela praticamente desaparece nos livros mais recentes. Essa mudança, se dá, em boa medida, pelas referências historiográficas que servem de apoio aos autores dos livros. Naquelas décadas, percebemos uma forte influência do trabalho de Thomas Skidmore que enfatiza sobremaneira a crise de 1961, ao passo que, nos livros produzidos após a década de 1980, percebemos uma grande influência da reflexão de René Dreifuss que minimiza essa crise. É interessante notar que o trabalho de Argelina Figueiredo ${ }^{17}$ do início dos anos 1990, que revaloriza a crise de 1961, é mencionada por apenas um dos livros analisados. Porém, em alguns momentos, percebemos que algumas obras citam os conflitos políticos de 1961-1964, sem se referir à renúncia de Jânio Quadros como o início da crise política.

Raymundo Campos, no livro História do Brasil (1983), ${ }^{18}$ destinado aos alunos do Ensino Médio, afirma que a crise desencadeada pela renúncia de Jânio Qua-

\footnotetext{
${ }^{15}$ Elian Alabi Lucci, História do Brasil: o império, a república e o Brasil contemporâneo, Ensino Médio, São Paulo, Saraiva, 1985, vol. 2, p. 93.

${ }^{16}$ Cláudio Vicentino, História: memória viva. Brasil: período imperial e republicano, São Paulo, Scipione, 1994, p. 118. O livro não diz a que série se destina.

${ }^{17}$ Ver Thomas E. Skidmore, Brasil: de Getúlio Vargas a Castelo Branco (1930-1964), São Paulo, Paz e Terra, 1969; René Armand Dreifuss, 1964. A conquista do Estado: ação política, poder e golpe de classe, Rio de Janeiro, Vozes, 1981; Argelina Cheibub Figueiredo, Democracia ou Reformas? Alternativas democráticas à crise política: 1961-1964, São Paulo, Paz e Terra, 1993.

${ }^{18}$ Raymundo Campos, História do Brasil, Ensino Médio, São Paulo, Atual, 1983.
} 
dros em setembro de 1961 quase levou o país a uma guerra civil e deixou grandes traumas. Somente o livro História Temática (2000), ${ }^{19}$ destinado à $8^{a}$ série, dos livros da década de 1990, destaca a crise de 1961 como início do processo que culminou no Golpe. Segundo Andréa Montellato, Conceição Cabrini e Roberto Catelli Junior, autores desse livro, "a crise que levou ao regime instaurado pelo golpe de Estado de 31 de março de 1964 teve início com a renúncia do presidente Jânio Quadros, em 1961".20

\section{“Origem": crise do populismo}

É interessante observar que esses autores e a maioria dos autores de livros didáticos analisados não procura definir ou problematizar o conceito de populismo. ${ }^{21}$ Aqueles que apontam a crise do populismo como uma das causas do golpe civil e militar abordaram o período de 1945-1964 como sendo o de uma experiência democrática em que o "povo" teve voz ativa. Adhemar Martins Marques, Ricardo de Moura Faria e Flávio Costa Berruti, autores do livro Brasil: História em Construção (1996), ${ }^{22}$ destinado ao Ensino Fundamental, exemplificam essa ausência de problematização. Segundo os autores, teria sido "no período em que Goulart governou que a crise do Populismo chegou a seu momento culminante". ${ }^{23}$

\footnotetext{
${ }^{19}$ Andréa Montellato; Conceição Cabrini; Roberto Catelli Junior, História Temática: O mundo dos cidadãos, $8^{\mathrm{a}}$ série, São Paulo, Scipione, 2000, pp. 226-227.

${ }^{20}$ Ibidem.

${ }^{21}$ Tendo em vista os limites deste artigo não pretendemos entrar nas complexas discussões historiográficas a respeito do conceito de populismo. Destacamos, no entanto, que para Ângela de Castro Gomes, o conceito de "populismo" foi visto como uma espécie de "mal" do privado e do público, constituindo-se na melhor tradução do impasse para a conquista da modernidade política. Porém, "numa leitura inversa e perversa, não foi o 'populismo' o que limitou nossa experiência democrática, mas o que a possibilitou". Ângela de Castro Gomes, "A política brasileira em busca da modernidade: na fronteira entre o público e o privado", In: Lilia Moritz Schwarcs, História da vida privada no Brasil: contrastes da intimidade contemporânea, São Paulo, Companhia das Letras, 2000, pp. 544-551. Para uma cartografia dos debates historiográficos ver Jorge Ferreira (org.), O populismo e sua história: debate e crítica, Rio de Janeiro, Civilização Brasileira, 2001.

${ }^{22}$ Adhemar Martins Marques; Ricardo de Moura Faria; Flávio Costa Berruti, Brasil: História em Construção, Ensino Fundamental, vol. 4, Belo Horizonte, Editora Lê, 1996, pp. 19-22.

${ }^{23}$ Ibidem. Francisco Alencar, Lúcia Carpi Ramalho e Marcus Venício Toledo Ribeiro, autores do livro História da Sociedade Brasileira, também apontam como causa do Golpe Militar a crise do populismo. Ver Francisco Alencar; Lúcia Carpi Ramalho; Marcus Venício Toledo Ribeiro, História da Sociedade Brasileira, Rio de Janeiro, Editora Ao Livro Técnico, 1985, p. 89.
} 
O que seria o populismo e quando a crise que terminaria com o Golpe teria tido início não são mencionados no decorrer do texto. Os autores afirmam que, no período do governo Goulart, a crise do populismo teria chegado a seu momento culminante sendo que "até o início de 1964 a crise só aumentou". Esse aumento da crise, de acordo com os autores do livro, gerou revolta e mobilização nas classes popular e empresarial e desencadeou o Golpe de $1964 .{ }^{24}$

Indiretamente, percebemos a influência das reflexões que consideram o populismo como uma manipulação política; afinal, seus líderes pertenciam às elites tradicionais e não se encontravam realmente vinculados a causas populares. Os trabalhos sobre o populismo entendem-no como um momento de transição de uma sociedade tradicional para a moderna, como uma etapa do desenvolvimento latino-americano, sendo a política de massas um momento necessário para a construção de uma sociedade desenvolvida e democrática, ou mesmo socialista. ${ }^{25}$ Notamos também que o progressivo questionamento desse conceito não está presente nos livros didáticos analisados. Essa ausência pode ser explicada, dentre outros motivos, pelo luto inacabado que ainda persiste quando se refere às análises acerca do Golpe, conforme destacaremos em nossas considerações finais.

\section{“Origem”: oposição ao governo de João Goulart}

Para Elian Alabi Lucci, autor do livro didático História do Brasil (1985), ${ }^{26}$ destinado ao Ensino Médio, "algumas atitudes do Presidente [João Goulart] começavam a encaminhar o País para a adoção de medidas de caráter esquerdista”. O autor não se preocupa em explicar que atitudes seriam essas, e continua, afirmando que "essas medidas provocaram agitações políticas e falta de disciplina, inclusive em alguns setores militares, o que gerou um clima de grande intranquilidade". ${ }^{27} \mathrm{O}$ que seriam medidas de caráter esquerdista? O que teria sido esse descontentamento nos âmbitos populares, políticos e militares? E qual seria a política imposta por Goulart? De acordo com o autor, o planejamento do Golpe Militar, denominado

\footnotetext{
${ }^{24}$ Ibidem.

${ }^{25}$ Ver Maria Helena Rolim Capelato, “Estado Novo: Novas Histórias”, In: Marcos Cezar Freitas (org.), Historiografia brasileira em perspectiva, São Paulo, Contexto, 1998, pp. 183-213.

${ }^{26}$ Elian Alabi Lucci, História do Brasil: o império, a república e o Brasil contemporâneo, Ensino Médio, São Paulo: Saraiva, 1985, vol. 2, pp. 93-94.

${ }^{27}$ Elian Alabi Lucci, História do Brasil: o império, a república e o Brasil contemporâneo, Ensino Médio, São Paulo, Saraiva, 1985, vol. 2, p. 93-94.
} 
"Revolução de março de 1964", teve início quando "começou a haver descontentamento nos âmbitos populares, políticos e militares. (...) os chefes militares, apoiados pelos governadores, organizaram um movimento que ficou conhecido como a Revolução de março de 1964 e que depôs João Goulart".28

Segundo Gilberto Cotrim, autor do livro História e reflexão (1996) ${ }_{, 2}^{29}$ destinado ao Ensino Fundamental, "João Goulart queria realizar um governo nacionalista e reformista", porém os grandes empresários nacionais e estrangeiros iriam reduzir seus "investimentos na produção, pois desconfiavam das intenções do governo. (...). Apavorados com a ideia de perder seus lucros e privilégios, os grandes empresários uniram-se aos militares. Começaram a tramar a queda de João Goulart". ${ }^{30}$ De acordo com Mário Furley Schmidt, autor do livro Nova História Crítica (1999), , destinado à $8^{\mathrm{a}}$ série, as reformas de base que seriam propostas por Jango em seu governo geraram uma mobilização popular que amedrontou as classes mais ricas. Essas classes tinham "medo de perder alguns privilégios"; temiam "que as Reformas de Base fossem apenas o começo de uma série de transformações radicais no país."32

\section{Outras "origens"}

Alguns livros destacam que as agitações políticas, durante o governo de Goulart, teriam desencadeado o Golpe de 1964. O comício realizado em 13 de março de 1964, a Marcha da Família com Deus pela Liberdade em 19 de março de 1964 e a Revolta dos Marinheiros em 25 de março do mesmo ano foram algumas dessas agitações políticas explicitadas pelos livros. Para outras obras, a incapacidade do governo de João Goulart foi uma das principais causas do Golpe Militar e civil. A incapacidade de João Goulart diz respeito às escolhas feitas por ele e a sua suposta covardia, demonstrada na sua fuga do Brasil no momento em que os militares tomavam o poder. Em 1983, por exemplo, Raymundo Campos, no livro História

\footnotetext{
${ }^{28}$ Ibidem.

${ }^{29}$ Gilberto Cotrim, História e reflexão, Ensino Fundamental, vol. 4, São Paulo, Saraiva, 1996, p. 115-117.

${ }^{30}$ Ibidem .

${ }^{31}$ Mário Furley Schmidt, Nova História Crítica, $8^{a}$ série, São Paulo, Editora Nova Geração, 1999, p. 235.

${ }^{32}$ Ibidem.
} 
do Brasil, ${ }^{33}$ destinado ao Ensino Médio, afirma que "o governo revelaria acentuada fraqueza, pressionado pela situação econômica, pela direita, pela esquerda, com reduzida margem de manobra”. Notamos que, na maioria dos livros didáticos das décadas de 1970 e 1980, os golpistas não seriam apontados como causa fundamental do Golpe. Nos livros dessa época, as origens do Golpe estão ligadas, em geral, a crises econômicas e à inabilidade de João Goulart no governo.

Nos livros das décadas seguintes, essas duas origens não aparecem; porém surgem quatro causas novas: choques entre grupos de esquerda e grupos de direita, fatos que ocorreram em março de 1964, política desenvolvimentista da década de 50 e $o$ golpe de 64 teria sido um adiamento do golpe planejado em 1961, após a renúncia de Jânio Quadros. Por economia de espaço, não detalharemos essas causas. ${ }^{34}$

\section{Pensar o "acontecimento traumático"}

Um aspecto que chama a atenção nos livros analisados é a ideia da inevitabilidade do Golpe de 1964, presente em todas as edições analisadas. De acordo com Francisco Alencar, Lúcia Carpi Ramalho e Marcus Venício Toledo Ribeiro, autores do livro História da Sociedade Brasileira (1985), ${ }^{35}$ por exemplo, "em meados de 1963, o Governo Goulart - que voltara ao presidencialismo por decisão de plebiscito realizado a 6 de janeiro - era obrigado a abandonar o Plano Trienal, revelando-se incapaz de sustar a crise econômica e financeira". Os autores afirmam que o primeiro gesto em oposição ao governo partiu da classe média. Esse movimento, para os autores, mais tarde teria se unido às conspirações que os grupos de oficias das Forças Armadas estavam tramando, conferindo-lhes, dessa forma, um apoio político e social. Ainda segundo esses autores, o apoio dos militares só aconteceu mais tarde. O golpe teria sido então inevitável, tornando-se uma consequência lógica das ações de Jango no governo.

\footnotetext{
${ }^{33}$ Raymundo Campos, História do Brasil, Ensino Médio, São Paulo, Atual, 1983, pp. 227-229.

${ }^{34}$ Sobre essas causas, ver Gilberto Cotrim, Saber e Fazer História: História Geral e do Brasil, 8 a série, São Paulo, Saraiva, 2000, pp. 136-139; Gleuso Damasceno Duarte, Jornada para o nosso tempo, 8aㅗ série, Belo Horizonte Editora Lê, 1997, vol. 4, p. 118; Kátia Corrêa Peixoto Alves; Regina Célia de Moura Gomide Belisário, Nas Trilhas da História, Ensino Fundamental, Belo Horizonte, Dimensão, 1999, vol. 4, pp. 184-185; Antônio Pedro, História do Brasil, Ensino Médio, São Paulo, FTD, 1987, p. 229.

${ }^{35}$ Francisco Alencar; Lúcia Carpi Ramalho; Marcus Venício Toledo Ribeiro, História da Sociedade Brasileira, 3.ed., Rio de Janeiro, Editora Ao livro Técnico, 1985.
} 
De acordo com Luciano Ramos, autor do livro História do Brasil (1977), ${ }^{36}$ destinado ao Ensino Fundamental, "a inflação crescia e, junto com ela, os preços e os problemas sociais. As crises administrativas se sucediam, ao lado das crises econômicas, da péssima situação financeira, da incapacidade administrativa”. A junção de todos esses fatores levou as Forças Armadas a intervir no processo político. Tropas do Exército se encaminharam para a Guanabara, a partir do dia 31 de março de 1964. "Em seguida, o presidente saiu do país e as Forças Armadas baixaram um Ato Institucional, que marcava a eleição de um novo presidente, pelo Congresso Nacional." ${ }^{37}$ Para Vanise Ribeiro, Virgínia Trindade Valadares e Sebastião Martins, autores do livro História: Assim Caminha a Humanidade (1993), ${ }^{38}$ destinado à $8^{a}$ série, em 1964 não houve uma mobilização democrática, como em 1961, para tentar impedir a ocorrência do golpe. Talvez esse seja um dos poucos exemplos onde há certa preocupação por parte dos livros analisados em se pensar sobre a "inevitabilidade do golpe ser dado" e também dele ser bem sucedido. Em geral, essas duas dimensões são confundidas. Afinal, mais do que a ocorrência do Golpe, a questão de fundo da maioria das pessoas e/ou pesquisas que se debruçam sobre este evento é a seguinte: por quais razões o Golpe de 1964 foi bem sucedido e duradouro do ponto de vista daqueles que foram vitoriosos?

Percebe-se, portanto, por meio desses exemplos e dos dados anteriores, que a inevitabilidade do Golpe (dele ser dado e ser bem sucedido) está presente, tanto nos livros cujos autores enfatizam a ideia de que 1964 foi fruto de uma conspiração, como naqueles em que se pensa o acontecimento como uma ação preventiva da direita em relação a uma futura ação da esquerda revolucionária. ${ }^{39}$

É interessante observar que, em 1994, dois importantes historiadores marxistas, Nelson Werneck Sodré e Jacob Gorender, negam a inevitabilidade do golpe. Respondendo à pergunta "seria possível evitar o golpe de 64?", Sodré afirmou:

\footnotetext{
${ }^{36}$ Luciano Ramos, História do Brasil, Ensino Fundamental, São Paulo, Editora do Brasil, 1977, vol. 2, p. 163.

${ }^{37}$ Ibidem.

${ }^{38}$ Vanise Ribeiro; Virgínia Trindade Valadares; Sebastião Martins, História: Assim Caminha a Humanidade, 8a série, Belo Horizonte, Editora do Brasil, 1993.

${ }^{39}$ Para uma análise dessas interpretações na historiografia do Golpe de 1964, ver, dentre outros, Lucilia de Almeida Neves Delgado, “1964: temporalidade e interpretações”, In: Daniel Aarão Reis; Marcelo Ridenti; Rodrigo Patto Sá Mota (orgs.), O golpe e a ditadura militar: 40 anos depois (19642004), São Paulo, Edusc, 2004.
} 
"Sim, teria sido se realmente nossas instituições fossem democráticas e sólidas. Não haveria as intervenções, nem os golpes, daí o cuidado que devemos ter, hoje, para que não haja uma ruptura no processo democrático." ${ }^{40} \mathrm{Na}$ mesma linha, Gorender afirmou que "visto de perspectiva ampla, o golpe não era inevitável. Contudo, tornou-se inevitável na curta conjuntura dos dois ou três meses que o antecederam. A derrota das correntes que a eles se opunham também não era inevitável". ${ }^{41}$ Portanto, gostaríamos de destacar, que, em geral, as diversas possibilidades "perdidas" pelos "atores" entre 1961-1964, as descontinuidades, "as alternativas disponíveis em conjunturas críticas durante a presidência de Goulart", ${ }^{42}$ não são mencionadas pelos livros analisados.

Refletir sobre o conceito de evento/acontecimento pode ser uma via interessante para se pensar o acontecimento para além de sua inevitabilidade. Cabe destacar, todavia, que, após a hegemonia das concepções braudelianas na década de 1970, que procuraram "aprisionar" o evento na curta duração, ${ }^{43}$ percebe-se que a disciplina história experimenta um retorno progressivo aos estudos sobre o acontecimento. ${ }^{44}$ Essas abordagens procuram entrar na temporalidade do próprio evento ao invés de negar o acontecimento ou de situá-lo em níveis de temporalidades hierarquicamente mais importantes.

Desse modo, acreditamos que o acontecimento não pode ser reduzido a um contexto ou a uma construção. ${ }^{45}$ Deve-se reconstruí-lo em sua especificidade

\footnotetext{
${ }^{40}$ Nelson Werneck Sodré, “Era o golpe de 64 inevitável?”, In: Caio Navarro de Toledo (org.), 1964: visões críticas do golpe, Campinas, Editora Unicamp, 1997, p.107.

${ }^{41}$ Jacob Gorender, “Era o golpe de 64 inevitável?”, In: Caio Navarro de Toledo (org.), 1964: visões críticas do golpe, Campinas, Editora Unicamp, 1997, p.114.
}

${ }^{42}$ Segundo Argelina Figueiredo, "entre 1961 e 1964, escolhas e ações específicas solaparam as possibilidades de ampliação e consolidação de apoio para as reformas, e, desta forma, reduziram as oportunidades de implementar, sob regras democráticas, um compromisso sobre estas reformas". Argelina Cheibub Figueiredo, Democracia ou Reformas? Alternativas democráticas à crise política: 1961-1964, São Paulo, Paz e Terra, 1993, p. 30. Ver, também, Argelina Cheibub Figueiredo, "Estruturas e escolhas: era o golpe de 1964 inevitável?", In: 1964-2004: 40 anos do golpe. Ditadura Militar e Resistência no Brasil. Rio de Janeiro, 7Letras: 2004 e Jorge Ferreira, A Democracia no Brasil (19451964). São Paulo, Atual, 2006.

${ }^{43}$ François Dosse, Império do sentido: a humanização das Ciências Humanas, Bauru, EDUSC, 2003.

${ }^{44}$ Jacques Revel, “Retour sur l'événement: un intinéraire historiographique”, In: Jean-Louis Fabiani (Dir.), Le Goût de l'Enquête: pour Jean-Claude Passeron, Paris, L'Harmattan, 2001.

${ }^{45}$ Ver Alban Bensa; Eric Fassin, “Les sciences sociales face à lévénement”, n. 38, Terrain, Paris, Éditions du Patrimoine, março 2002, pp. 5-20. 
temporal, como uma ruptura da inteligibilidade. ${ }^{46}$ Consideramos, desse modo, que os eventos partilham um tempo entre o passado e o futuro, um antes e um depois do Golpe Militar de 1964, por exemplo. ${ }^{47} \mathrm{O}$ acontecimento, mesmo que traumático, é uma linha divisória imaterial, que abre e fecha séries de diversos e múltiplos horizontes temporais que não se resumem à epifania do instante, apesar de comportar essa dimensão também.

Portanto, é no entrecruzamento de durações que se ancora a dinâmica histórica dos atores que se movimentam em várias temporalidades, na maioria das vezes, não lineares, como podemos perceber quando analisamos o jogo entre determinações e indeterminações que possibilitaram o Golpe de 1964. Acreditamos, desse modo, que pensar e trabalhar sobre o conceito de acontecimento pode nós auxiliar a romper com as amarras impostas pela ideia de inevitabilidade tal como encontramos nos livros didáticos analisados. ${ }^{48}$

\section{Livros didáticos e causalidade}

Para problematizar a ideia de inevitabilidade, seria necessário, a nosso ver, rompermos com o conceito de causalidade linear ou mesmo, talvez, superar a concepção de causalidade. Porém, podem os autores, em livros como os didáticos, realizar ou ousar a esse ponto?

Para Marisa Lajolo, didático é "o livro que vai ser utilizado em aulas e cursos, que provavelmente foi escrito, editado, vendido e comprado, tendo em vista essa utilização escolar e sistemática" ${ }^{49}$ Para que se possa considerar um livro

\footnotetext{
${ }^{46}$ Ver, por exemplo, Gilles Deleuze, Lógica do Sentido, São Paulo, Perspectiva, 1974, p. 152.

${ }^{47}$ A esse respeito Koselleck afirma que "a unidade de sentido que faz dos diferentes acontecimentos um acontecimento é composta de um mínimo de 'antes' e 'depois"'. Reinhart Koselleck, Futuro Passado: contribuição à semântica dos tempos históricos, 1.ed., Rio de Janeiro, Contraponto, 2006, p. 134. Vale a pena destacar que para Koselleck o acontecimento é irredutível, pois ele é constituído por um "nó" de temporalidades atualizadas em um momento dado. Os acontecimentos são prisioneiros de um antes e de um depois, ligados à cronologia e empiricamente verificados. Porém, essa dimensão deve dialogar com a dimensão estrutural e conceitual, pois os acontecimentos e estruturas são, ao mesmo tempo, abstratos e concretos.

${ }^{48}$ François Dosse comentando a obra de Deleuze afirma, paradoxalmente, que tentar compreender e explicar um acontecimento em sua complexidade e lógicas de sentidos coloca em crise diversas concepções de história. François Dosse. Gilles Deleuze et Félix Guattari. Biographie croisée, Paris, Decouvert, 2007, pp. 384-388.

${ }^{49}$ Marisa Lajolo, "Livro Didático: um (quase) manual de usuário”, Em aberto, 16 (69): 3-9, Brasília, jan/mar, 1996, p. 4.
} 
como didático, ele deve ser utilizado de forma sistemática no processo de ensinoaprendizagem. Ele se dirige, ao mesmo tempo, a dois leitores distintos, o professor e o aluno. Assim como qualquer outro livro, o didático proporcionará leituras diferentes para leitores diferentes.

É importante perceber que os livros didáticos não são uma mera transposição de um saber acadêmico para um saber escolar. As disciplinas escolares não são reflexo nem vulgarização dos saberes da pesquisa acadêmica. ${ }^{50}$ Ensinar, não é, portanto, simplificar e vulgarizar. Deveria ser, antes de tudo, fazer pensar, problematizar.

No entanto, percebemos que, no afã de hierarquizar e citar as origens do acontecimento, no caso, o Golpe de 1964, a interpretação e a análise são deixadas de lado em certos aspectos pelos autores de livros didáticos. Seria necessário pensar a história para além da fascinação pela origem. Afinal, a contradição que os historiadores das origens pretendem superar é, em certa medida, insuperável, pois, após uma longa busca das causas "profundas" e "imediatas", eles retornam sempre ao caráter contingente do começo de uma guerra, ${ }^{51}$ conflito e, no nosso caso, do Golpe Militar de 1964. François Furet, ao analisar a 1 ${ }^{\text {a }}$ Guerra Mundial, afirmou que quanto mais pesadas, fortes e traumáticas forem as consequências de um evento, mais difícil é pensá-lo a partir de suas causas. ${ }^{52}$

De qualquer maneira, no que se refere ao Golpe de 1964, tendemos a concordar com Lucilia Delgado, quando afirma que pensar as razões de aconteci-

\footnotetext{
${ }^{50}$ André Chervel, "História das disciplinas escolares: reflexões sobre um campo de pesquisa”, Teoria e Educação, n. 2, 1990, p. 182. Ver, também, Circe Bittencourt, Ensino de História: fundamentos e métodos, São Paulo, Cortez, 2004.

${ }^{51}$ Antoine Prost, Jay Winter, Penser la Grande Guerre: un essai d'historiographie, Paris, Seuil, 2004, p .63.

${ }^{52}$ Jacques Revel, “Retour sur l'événement: un intinéraire historiographique”, In: Jean-Louis Fabiani (Dir.), Le Goût de l'Enquête: pour Jean-Claude Passeron, Paris, L'Harmattan, 2001, p. 102. Cabe aqui destacar a definição de contigência de Raymond Aron: "nous entendons par contingence à la fois la possibilité de concevoir l'événement autre et l'impossibilité de déduire l'événement d'ensemble de la situation antérieure". Raymond Aron, Introduction à la philosophie de l'histoire. Essais sur les limites de l'objectivité historique, Paris, Gallimard, 1986, p. 277. Umberto Eco, em O Nome da Rosa, apresenta-nos um comentário que julgamos pertinente, a saber : “(..) porque raciocinar sobre as causas e sobre os efeitos é coisa muito difícil, creio que o único juiz possível é Deus. Já temos a maior dificuldade em apreender uma relação entre um efeito tão evidente como um árvore queimada e o raio que a incendiou: assim, remontar encadeamentos às vezes muito longos de causas e efeitos parece-me tão louco quanto procurar construir uma torre que vá até o céu”. Citado por Miles Hewstone, "Representações sociais e causalidade", Denise Jodelet (org.), As representações sociais, Rio de Janeiro, EDUERJ, 2001, p. 217.
} 
mentos como o Golpe "é tarefa complexa, supõe identificação e compreensão da multiplicidade de variáveis presentes nas conjunturas que precedem essas rupturas e supõe também identificação de elementos de longa duração que se atualizam nessas conjunturas" ${ }^{53}$ Há, assim, um entrecruzamento de tempos históricos de longa e curta duração, "conformando uma crise complexa, que não cabe ser interpretada através de qualquer tipo de esquema teórico preestabelecido, pois cada dinâmica histórica é singular". ${ }^{54}$

Na mesma direção, Carlos Fico afirma que, sem a desestabilização ocasionada pela propaganda ideológica e a mobilização da classe média, além de uma mínima coordenação e planejamento da ação militar, o Golpe de 1964 seria difícil de eclodir. As mudanças estruturais do capitalismo brasileiro, a instabilidade institucional do país, as incertezas do governo de João Goulart, a propaganda política conservadora, a natureza golpista dos conspiradores, especialmente a dos militares, são causas "macroestruturais ou micrológicas", "que devem ser levadas em conta, não havendo nenhuma fragilidade teórica em considerarmos como razões do golpe tanto os condicionantes estruturais quanto os processos conjunturais ou os episódios imediatos". ${ }^{55}$

Nessa busca de sentido sem teleologia, ligada à crise do causalismo ou do monocausalismo, François Dosse nos convida a pensar também em subdeterminações, isto é, irreduções que não podem ser pensadas linearmente a partir de relações de causalidades, nas quais os fenômenos anteriores determinariam os que seguem. "A noção de subterminação designa ao mesmo tempo a pluralidade dos possíveis e a existência de constrangimentos que têm como efeito que alguns possíveis aconteçam, e outros não." ${ }^{56} \mathrm{~A}$ indeterminação não é uma indistinção postulada, absoluta, pois a reabertura do campo múltiplo das possibilidades do passado não é infinita. Trata-se, de inscrever as possibilidades de interpretação no interior das limitações, como podemos perceber a partir do trabalho de Argelina Chei-

\footnotetext{
${ }^{53}$ Lucilia de Almeida Neves Delgado, “1964: temporalidade e interpretações”, In: Daniel Aarão Reis; Marcelo Ridenti; Rodrigo Patto Sá Mota, O golpe e a ditadura militar: 40 anos depois (1964-2004). São Paulo, Edusc, 2004, p. 26.

${ }^{54}$ Idem.

${ }^{55}$ Carlos Fico, "Versões e controvérsias sobre 1964 e a ditadura militar", Revista Brasileira de História, vol. 24, n. 47, São Paulo, 2004, pp. 29-60.

${ }^{56}$ François Dosse, Império do sentido: a humanização das Ciências Humanas, Bauru, EDUSC, 2003, p. 333.
} 
bub Figueiredo ${ }^{57}$ e das análises presentes, em especial, no livro História Temática (2000), como já referimos. Ao que parece, pensar em narrativas didáticas que questionem o causalismo é pensar uma didática da história em direção à complexidade. Complexidade do tempo, da história e da ação. É preciso, a nosso ver, que os textos didáticos mostrem e demonstrem para os homens de hoje que é melhor para a vida compreender o tempo como "folheado", "múltiplo" e "multidirecionado".

As diversas possibilidades "perdidas" pelos "atores" entre 1961-1964, as descontinuidades, "as alternativas disponíveis em conjunturas críticas durante a presidência de Goulart" ${ }^{\prime 8}$ não são mencionadas por nenhum dos 60 livros analisados.

Percebemos, assim, que a fascinação pela ideia de origem, denunciada por Marc Bloch ${ }^{59}$ na primeira metade do século XX, permeia todos os livros didáticos analisados. Dessa maneira, dada a intencionalidade didática do saber histórico escolar veiculado nas obras analisadas, seria importante relativizar - e não abolir - noções determinantes como "origem" e/ou causa. Seria um grande passo para que os livros didáticos de História assumissem um conceito de tempo mais heterogêneo e plural, como inclusive é sugerido pelos atuais Parâmetros Curriculares Nacionais de História (PCN’s). ${ }^{60}$ Pensamos que as dificuldades em se

${ }^{57}$ Argelina Cheibub Figueiredo, Democracia ou Reformas? Alternativas democráticas à crise política: 1961-1964, São Paulo, Paz e Terra, 1993. Não se trata aqui de criticar alguns livros a partir de critérios estabelecidos posteriormente. Mas, de mostrar que a concepção de história que privilegia as "possibilidades perdidas" e/ou "disponível" não está presente nos livros analisados. Pretendeu-se, portanto, assumir a concepção de que a história da historiografia deve refletir sobre as memórias construídas, na medida em que a historiografia pode ser compreendida como "investigação sistemática acerca das condições de emergência dos diferentes discursos sobre o passado”. Manuel L. L. S. Guimarães, "Memória, história e historiografia”. In: José Neves Bittencourt, Sara Fassa Benchetrit, Vera Lúcia Bottrel Tostes (orgs.). História representada: o dilema dos museus, Rio de Janeiro, Museu Histórico Nacional, 2003, p. 92.

${ }^{58}$ Segundo Argelina Figueiredo, "entre 1961 e 1964, escolhas e ações específicas solaparam as possibilidades de ampliação e consolidação de apoio para as reformas, e, desta forma, reduziram as oportunidades de implementar, sob regras democráticas, um compromisso sobre estas reformas". Argelina Cheibub Figueiredo, Democracia ou Reformas? Alternativas democráticas à crise política: 1961-1964, São Paulo, Paz e Terra, 1993, p. 30. Ver, também, Argelina Cheibub Figueiredo, "Estruturas e escolhas: era o golpe de 1964 inevitável?", In: 1964-2004: 40 anos do golpe. Ditadura Militar e Resistência no Brasil, Rio de Janeiro, 7Letras, 2004 e Jorge Ferreira, A Democracia no Brasil (19451964), São Paulo, Atual, 2006.

${ }^{59}$ Ver Marc Bloch, Apologia da História, ou o ofício do historiador, Rio de Janeiro, Zahar, 2001.

${ }^{60}$ Baseado em categorias braudelianas, o documento privilegia os eixos temáticos sobre a cronologia: "Os ritmos da duração, por sua vez, possibilitam identificar a velocidade com que as mudanças ocorrem. Assim, podem ser identificados três tempos: o tempo do acontecimento breve, o da 
trabalhar com um conceito de história mais complexo poderiam ser vencidas, ao menos parcialmente, introduzindo, nos livros didáticos, noções de indeterminação e subdeterminação. Em outras palavras, trata-se de considerar o(s) tempo(s) histórico(s) como plural, folheado e multidirecionado. Obviamente, essas mudanças devem ser trabalhadas nos cursos de graduação que formam os professores de história, futuros compradores indiretos dos livros.

Até que ponto, por exemplo, nas disciplinas ditas de "conteúdo" dos cursos de graduação, essas análises e a recusa da obsessão pelas origens são levadas em consideração? É preciso ainda um longo trabalho, para, nos termos de Paul Ricoeur, renunciar a Hegel. ${ }^{61}$ Afinal, como destaca Krzysztof Pomian, as periodizações que levam a pensar o tempo histórico como linear só surgem após Hegel. ${ }^{62}$ Seria interessante se os professores, alunos, autores e editoras ousassem em nome da vida; afinal, como Marc Bloch aponta, "nesta faculdade de apreensão do que é vivo é que reside, efetivamente, a qualidade fundamental do historiador". ${ }^{63}$ Essa mudança de procedimento, atitude e postura frente às construções de sentido do passado poderia contribuir para mostrar que a história é antes de tudo uma construção e não um dado natural.

Os diversos sentidos que o Golpe de 1964 assume nas narrativas dos livros didáticos de História analisados em nossa pesquisa possibilitam compreender e explicar aspectos do processo de construção de sentidos desse "acontecimento traumático" em obras didáticas, de 1970 a 2000. As narrativas que reorganizam o acontecimento, em sua pluralidade, são indissociáveis dele, formam parte da trama do acontecimento. ${ }^{64} \mathrm{~A}$ insistente ideia de interpretar o acontecimento, partindo de causas e efeitos, não permite análises didáticas que desconstruam, que evidenciem as descontinuidades. E, sobretudo, procurem conciliar descontinuidade e continuidade.

conjuntura e o da estrutura." Brasil, Secretaria de Educação Fundamental. Ministério da Educação, Parâmetros curriculares nacionais: História e Geografia, Brasília, 1998, vol. 5, p. 38.

${ }^{61}$ Paul Ricoeur, Temps et récit. 3: Le temps raconté. Paris, Seuil, 1985, pp. 349-372.

${ }^{62}$ Krzysztof Pomian, Periodização, Enciclopédia Einaudi, vol. 29, Tempo/temporalidade, Lisboa, Impressa Nacional, 1993, pp. 164-213.

${ }^{63}$ Marc Bloch, Apologia da História, ou o ofício do historiador, Rio de Janeiro, Zahar, 2001, pp. 42 e 46.

${ }^{64}$ Para François Dosse "independentemente dos atores do acontecimento, a evolução das representações deste, a diversidade das narrativas às quais ele dá origem fazem totalmente parte do acontecimento em si em sua eficácia flutuante ao longo do tempo". François Dosse, História e Ciências Sociais, São Carlos, EDUSC, 2004, p. 65. 


\section{Considerações finais}

A história transforma o trabalho de memória em um trabalho de luto. Muitas vezes, essa é uma forma de retirar dor dos objetos históricos, interiorizando-os, principalmente quando estamos na "onda de choque" do "evento traumático".65 Pensar sobre os sentidos atribuídos ao Golpe pelos autores de livros didáticos de história é, ao mesmo tempo, portanto, um trabalho de memória e um trabalho de luto. Porém, sabemos que o luto inacabado não permite a edificação de uma tumba escriturária, que seria uma história com "distanciamento". ${ }^{66}$ Além disso, o historiador-autor de livros didáticos teria determinadas "identificações" em relação ao acontecimento que são próprias ao seu ofício, mas que seriam agravadas quando ele participa de tal conjuntura. O poder traumático dos eventos talvez possa não ter sido totalmente absorvido no momento em que ele escreveu. A dificuldade, nesses casos, não é apenas conceituar e interpretar bem, mas fazer corretamente o trabalho de luto. A fim de que o evento não caia no esquecimento e/ou impeça ao presente de criar o novo. ${ }^{67}$

Entendemos que os "novos" sentidos que viriam a ser atribuídos ao Golpe, principalmente nos livros didáticos mais recentes, marcam também o começo do trabalho de memória. Esse dado pode ser demonstrado pela ausência de determinadas "origens" como incapacidade de Goulart. A retirada da dor dos objetos e sua interiorização parecem ter sofrido uma diminuição; afinal, o aumento de explica-

\footnotetext{
${ }^{65}$ Paul Ricoeur, Écrire L'Histoire du Temps Present, Paris, Seuil, 1991. Para uma análise das relações entre história e psicanálise, em especial, do conceito de trauma e a dialética entre passado e presente, ver François Dosse, História e Ciências Sociais, São Carlos, EDUSC, 2004, p. 65.

${ }^{66}$ Paul Ricoeur, "Memoire: approches historiennes, approche philosophique", In: Le Débat, Paris, Galimard, 2002, pp. 41-61, pp. 59-61.

${ }^{67}$ Paul Ricoeur, La mémoire, l'histoire, l'oubli, Paris, Seuil, 2000. Hannah Arendt afirmou que a única solução possível para o problema da irreversibilidade, entendida como sendo a impossibilidade de se "desfazer o que se fez, embora não se soubesse nem se pudesse saber o que se fazia - é a faculdade de perdoar. A solução para o problema da imprevisibilidade, da caótica incerteza do futuro, está contida na faculdade de prometer e cumprir promessas". Hannah Arendt. A condição humana, São Paulo, Universitária, 1991, p. 249. Ricoeur, por sua vez, concorda em parte com Hannah Arendt, mas ele avança no sentido de acreditar que a concessão do perdão está fundamentada no desligamento do ato de seu agente. O perdão é sempre dirigido ao outro e não à ação mesma. Da nossa parte, o que é importante destacar é que é preciso pensar uma educação histórica que se preocupe em evitar a repetição de qualquer evento semelhante a 1964. Pensamos que a lembrança, a reflexão, a interpretação e uma possível reconciliação crítica em relação ao "acontecimento traumático" pode ser um passo importante nesse tipo de educação histórica.
} 
ções mais ricas e menos simplistas nas narrativas didáticas acerca do Golpe de 1964 aparentam isso. Podemos dizer que os livros didáticos analisados, uns mais do que outros, é verdade, foram importantes "atores" nesse processo de retirada da dor desse "acontecimento traumático" e também terrível que não deve ser esquecido. Desse modo, "manter presente o acontecimento" para guardá-lo como algo a ser pensado é uma forma de impedir sua dispersão no tempo e no esquecimento. ${ }^{68}$

\section{Anexo 1 - Livros didáticos citados pelo texto (por década de edição)}

\section{0}

RAMOS, Luciano. História do Brasil. Ensino Fundamental. São Paulo: Editora do Brasil, 1977, $2^{\circ}$ vol.

SANTOS, Maria Januária Vilela. História do Brasil. $6^{\circ}$ série. São Paulo: Ática, 1979.

\section{0}

ALENCAR, Francisco, RAMALHO, Lúcia Carpi, RIBEIRO, Marcus Venício Toledo. História da Sociedade Brasileira. Rio de Janeiro: Editora do livro Técnico, 1985.

CAMPOS, Raymundo. História do Brasil. Ensino Médio. São Paulo: Atual, 1983. LUCCI, Elian Alabi. História do Brasil: O império, a república e o Brasil contemporâneo. Ensino Médio. São Paulo: Saraiva, 1985, vol. 2.

PEDRO, Antônio. História do Brasil. Ensino Médio. São Paulo: FTD, 1987.

\section{0}

ALVES, Kátia Corrêa Peixoto, BELISÁRIO, Regina Célia de Moura Gomide. História. Ensino Fundamental. Belo Horizonte: Vigília, 1991, vol 4.

. Nas Trilhas da História. Ensino Fundamental. Belo Horizonte: Dimensão, 1999, vol. 4.

${ }^{68}$ Ver Irene de Arruda Ribeiro Cardoso, "Foucault e a noção de acontecimento", Tempo Social, n. 7, vol. 1-2, São Paulo, USP, 1995, pp. 57-58. 
COTRIM, Gilberto. História e reflexão. Ensino Fundamental. São Paulo: Saraiva, 1996, vol. 4.

DUARTE, Gleuso Damasceno. Jornada para o nosso tempo. $8^{\text {a }}$ série. Belo Horizonte: Editora Lê, 1997, vol. 4

MARQUES, Adhemar Martins; FARIA, Ricardo de Moura; BERRUTI, Flávio Costa. Brasil: História em Construção. Ensino Fundamental. Belo Horizonte: Lê, 1996, vol. 4.

RIBEIRO, Vanise; VALADARES, Virgínia Trindade; MARTINS, Sebastião. História: Assim Caminha a Humanidade. $8^{\circ}$ série. Belo Horizonte: Editora do Brasil, 1993.

SCHMIDT, Mário Furley. Nova História Crítica. 8 $8^{\mathrm{a}}$ série. São Paulo: Editora Nova Geração, 1999.

VICENTINO, Cláudio. História Memória Viva. Brasil Período imperial e republicano. São Paulo: Scipione, 1994.

2000

COTRIM, Gilberto. Saber e Fazer História: História Geral e do Brasil. $8^{\circ}$ série. São Paulo: Saraiva, 2000.

MONTELLATO, Andrea; CABRINI, Conceição; CATELLI JUNIOR, Roberto. História Temática: O mundo dos cidadãos. 8ª série. São Paulo: Scipione, 2000.

Anexo 2 - Demais livros didáticos utilizados pela pesquisa (por década de edição)

1970

ABRAMO, Alcione. Ensino criativo de História do Brasil. Império e República. $1^{\circ}$ grau. 6a série. São Paulo: Editorado Brasil, 1976.

ARRUDA, José Jobson de A. História: Moderna e Contemporânea. Ensino Médio. São Paulo: Ática, 1977.

FERREIRA, Olavo Leonel. História do Brasil. $2^{\circ}$ grau. São Paulo: Editora Ática, 1978. 
FILHO, Arnaldo Fazoli. História do Brasil. 2ºrau. São Paulo: Editora Brasil, 1977.

GOMES, Paulo Miranda. História do Brasil. $1^{\circ} \mathrm{grau}$. Belo Horizonte: Editora Lê, 1973, vol. II.

, MOURA, Nelson de, GONZALEZ, Alaíde Inah. História Geral da Civilização Brasileira. Ensino Médio e Concursos vestibulares. Belo Horizonte: Lê, 1976.

HERMIDA, Antônio José Borges. História do Brasil 2.1ํ grau. São Paulo: Editora Nacional, 1978.

HOLLANDA, Sérgio Buarque de.História do Brasil 2:da Independência aos nossos dias. $6^{a}$ série. $1^{\circ}$ grau, estudos sociais. São Paulo: Editora Nacional, 1973.

LUCCI, Elian Alabi. Trabalho Dirigido de História do Brasil. $2^{\circ}$ grau. São Paulo: Saraiva, 1979.

MAIOR, A. Souto. História do Brasil. $2^{\circ}$ grau. São Paulo: Editora Nacional, 1974. VALUCE, Ládmo. História do Brasil. Ensino Fundamental. São Paulo: Editora do Brasil, 1973.

\section{0}

ALCANTRA, Paulo César de. História do Brasil: República e tempos atuais. SP: Editora do Brasil, 1982.

ARAÚJO, Antoracy Tortorelo. História do Brasil: Independência e Luta democrática. Ensino Fundamental. São Paulo: Editora do Brasil, 1985.

AZEVEDO, L. de; DAROS, Vital. A história de um povo. Sociedade Brasileira, Império e Republica. São Paulo: FTD, 1988, vol. 2.

BARBOSA FILHO, Milton Benecto, STOCKER, Maria Luíza Santiago. História do Brasil do Império a República. São Paulo: Scipione, 1988.

CARMO, Sonia Irene do, COUTO, Eliane. História do Brasil. $1^{\circ}$ grau. Brasil Império e Republica. São Paulo: Atual, 1989, $2^{\circ}$ vol.

DOMINGUES, Joelza Ester; LEITE, Layla Paranhos. Brasil: uma perspectiva histórica. $2^{\circ}$ grau. São Paulo: FTD, 1983.

KOSHIBA, Luiz; PEREIRA, Denise Manzi Eraeyze. História do Brasil. São Paulo: Atual, 1987. 
MARQUES, Adhemar Martins, FARIA, Ricardo de Moura, BERRUTI, Flávio Costa. História. Ensino Fundamental. Belo Horizonte: Lê, 1989, vol. 2. . História. Ensino Médio. Belo Horizonte: Lê, 1989. vol. 3.

PILETTI, Nelson. História do Brasil. Ensino Médio e vestibulares. São Paulo: Ática, 1982.

\section{0}

ALVES, Kátia Corrêa Peixoto; BELISÁRIO, Regina Célia de Moura Gomide. História. Ensino Fundamental. Belo Horizonte: Vigília, 1990, vol. 4.

História: Os Rumos da Humanidade. 8ª série. Belo Horizonte: Vigília, 1994.

ARRUDA, José Jobson. História Integrada. Do fim do século XIX aos dias de hoje. São Paulo: Editora Ática, 1995, vol. 4.

BARBOSA FILHO, Milton Benecto, STOCKER, Maria Luíza Santiago. História do Brasil do Império a República. São Paulo: Scipione, 1993.

BOULOS JÚNIOR, Alfredo. História do Brasil. Império e Republica. São Paulo: FTD, 1995, vol. 2.

CAMPOS, Raymundo. História do Brasil. Ensino Fundamental. São Paulo: Atual, 1991, vol. 2.

COSTA, Luís César Amad; MELLO, Leonel Itaussu A.. História do Brasil. Ensino Médio. São Paulo: Scipione, 1991.

DUARTE, Gleuso Damasceno. Jornada para o nosso tempo. 8 $8^{\mathrm{a}}$ série. Belo Horizonte: Lê, 1997. vol. 4.

COTRIM, Gilberto. História e Consciência do Brasil. Ensino Médio. São Paulo: Saraiva, 1995.

. História Global: Brasil e Geral. Ensino Médio. São Paulo: Saraiva, 1997, vol. único. vol. único.

. História Global: Brasil e Geral. Ensino Médio. São Paulo: Saraiva, 1998, História Global: Brasil e Geral. Ensino Médio. São Paulo: Saraiva, 1999, vol. único.

GIOVANNI, Cristina Visconti, JUNQUEIRA, Zilda Almeida, TUONO, Silvia Guena. História: Compreender para aprender. 8a série. São Paulo: FTD, 1998. 
MARANHÃO, Ricardo; ANTUNES, Maria Fernanda. Trabalho e Civilização: Uma História Global. O mundo contemporâneo (do século XIX aos Dias Atuais). Ensino Fundamental. São Paulo: Editora Moderna, 1999, vol. 4.

MARQUES, Adhemar Martins; FARIA, Ricardo de Moura; BERRUTI, Flávio Costa. História: Os Caminhos do Homem. Ensino Fundamental. Belo Horizonte: Lê, 1991, vol. 4.

MARQUES, Adhemar Martins; FARIA, Ricardo de Moura; BERRUTI, Flávio Costa. História. Ensino Médio. Belo Horizonte: Lê, 1993, vol. 3. . História. Ensino Médio - vol. 2. Belo Horizonte: Lê, 1995. . História. Ensino Médio. Belo Horizonte: Lê, 1997, vol. 3. MARTINS, José Roberto Ferreira. História. 8ª série. São Paulo: FTD, 1990. MOTA, Myriam Becho; BRAICK, Patrícia Ramos. História das Cavernas ao Terceiro Milênio. Ensino Médio. São Paulo: Moderna, 1997.

PILETTI, Nelson; PILETTI, Claudino. História e Vida. Ensino Fundamental. São Paulo: Ática, 1991.

PILETTI, Nelson. História do Brasil: Da Pré-História do Brasil aos Dias Atuais. São Paulo: Ática, 1991. Ática, 1993.

. História do Brasil: Da Pré-História do Brasil aos Dias Atuais. São Paulo: . História do Brasil: Da Pré-História do Brasil aos Dias Atuais. Ensino Médio. São Paulo: Ática, 1996.

PILETTI, Nelson; ARRUDA, José Jobson de A.. Toda a História: História Geral e História do Brasil. Ensino Médio. São Paulo: Ática, 1995.

. Toda a História: Historia Geral e Historia do Brasil. Ensino Médio. São Paulo: Ática, 1997.

RIBEIRO, Vanise; ANASTASIA, Carla. Brasil: Encontros com a História. Ensino Fundamental. São Paulo: Editora do Brasil, 1996, vol. 4.

. Brasil: Encontros com a História. Ensino Fundamental. São Paulo: Editora do Brasil, 1999, vol. 4.

RIBEIRO, Vanise; TRINDADE, Virginia; MARTINS, Sebastião. História: Assim Caminha a Humanidade. São Paulo: Editora do Brasil, 1999, vol.4. 
VICENTINO, Cláudio. História Integrada: Brasil e Geral. O século XX. 8ª série. São Paulo: Scipione, 1995.

2000

BERUTTI, Flávio. História: Tempo e espaço. $8^{\mathrm{a}}$ série. Belo Horizonte: Editora Formato, 2002.

COTRIM, Gilberto. História: Brasil e Geral. Ensino Médio. São Paulo: Saraiva, 2002, vol. único.

. Saber e Fazer História: História Geral e do Brasil. Mundo Contemporâneo e Brasil República. 8a série. São Paulo: Saraiva, 2004.

MORAES, José Geraldo Vinci de. História Geral e Brasil. Ensino Médio. São Paulo: Atual, 2003, vol. único.

PILETTI, Nelson; PILETTI, Claudino. História e Vida. $8^{\text {a }}$ série. São Paulo: Ática, 2000.

História e Vida Integrada. São Paulo: Ática, 2002.

RODRIGUES, Joelza Ester. História em Documento: Imagens e Texto. São Paulo: FTD, 2000.

VICENTINO, Cláudio. História. 8ª série. São Paulo: Scipione, 2005. 